\title{
Calculating pregnancy's duration in ancient greece. gestational, or fetal age?
}

\begin{abstract}
Ancient Greek women, midwifes and medico-philosophers used for the calculation of the pregnancy's duration a series of calendars like the Attica and Lunisolar ones. Hippocrates was the first physician who wondered about the starting point for its calculation, gestational age, or fetal age. Our study indicates that ancient Greek were undecided on the matter. Various theories were suggested for the total duration, in months and days. Hippocrates and Galen introduced a period between 270 and 280 days for a normal 9 month pregnancy, while Aristotle suggested more complex theories based on the species. Oribasius, surprisingly recorded his own peculiar theory of an unspecified period, proposing an interval of 184 up to 204 days.
\end{abstract}

Volume 6 Issue 3 - 2017

\author{
Gregory Tsoucalas,' 'Markos Sgantzos',2 \\ History of Medicine, University of Thessaly, Greece \\ ${ }^{2}$ Anatomy Department, University of Thessaly, Greece
}

Correspondence: Gregory Tsoucalas, lerolohiton 155, Agioi Anargyroi 38334,Volos, Greece, Tel 00306945298205 , Email gregorytsoucalas@yahoo.gr

Received: October 27, 2016 | Published: March 06, 2017

Keywords: Ancient Greece, Calculating pregnancy's duration, Gestational age, Fetal age, calendars

\section{Introduction}

The experience of childbirth is an important life event for all women, which may follow them throughout their lifetime. In antiquity, childbirth was mostly considered a matter for women and took place in a metaphorically said, a closed holy room, where only the pregnant, female relatives or caregivers and midwifes, all female personnel was allowed. Mythology, ancient tales, and epic poems, all testify since earliest times to the existence of a female knowledge of obstetric tasks. Women in ancient Greece were able to use a calendar or a symbosia list (festivals of the era) (Figure 1) to find the most fruitful period foe sexual interaction to get pregnant, and always searched the most suitable weather and environmental conditions related to the hygiene of the era. A pregnant woman (Figure 2) was protected by the laws of the state, and was entitled to acquire any heritage in the case of a husband's death. ${ }^{1-3}$

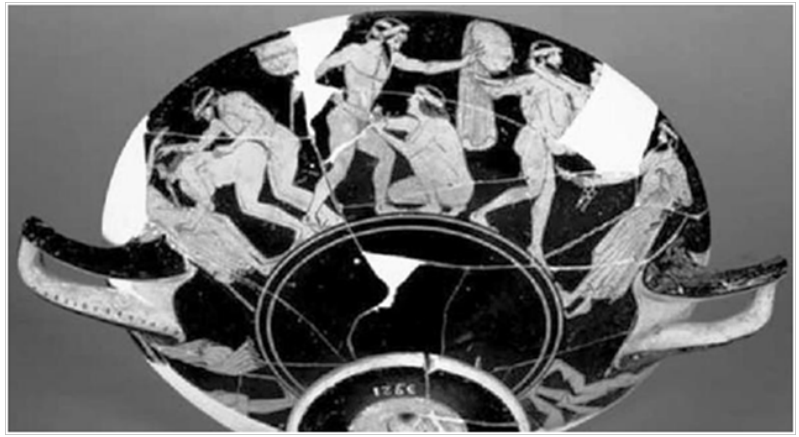

Figure I Scenes from a symposion, Attic red-figure kylix, ca 490-480 BC, Florence, National Archaeological Museum, inv. no. 3921.

In ancient Greece, women were capable to calculate the pregnancy duration by using a series of calendars, like the Attica calendar (12 months, trimester season, Athenian calendar) (Figure 3), the Lunisolar calendar (Figure 4) (the first sighting of the new moon after the summer solstice), and surprisingly the "Frying Pan" vessels (terracotae Teganoschema) (Figure 5), which reveal a symbolic writing that depicts astronomical phenomena, that are complex calendars based on the Sun and the Moon and all then known planets. Someone could wonder about the starting point for the calculation. Ancient Greeks used what we call today the "gestational age", the common term used during pregnancy to describe how far along the pregnancy is, measured in weeks, from the first day of the woman's last menstrual cycle to the current date and/or fetal age, the actual age of the growing baby, numbering as first the day of conception. ${ }^{1,4}$

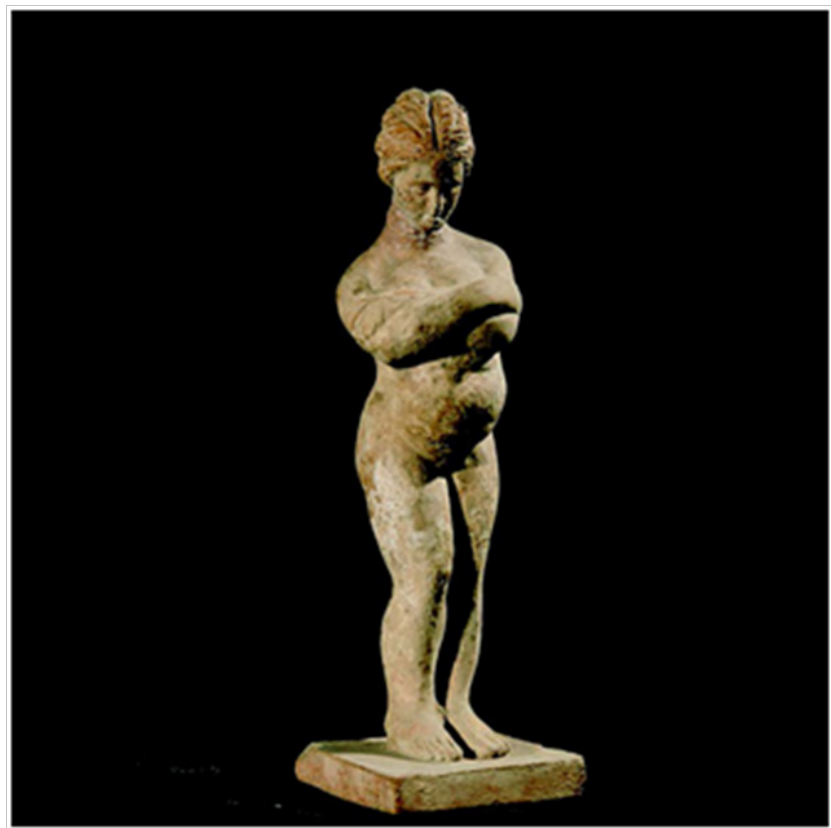

Figure 2 Pregnant nude. Terracotta figurine (early 3rd BC) from Tanagra, Boeotia, Greece.

Our study, completed a thorough search inside the available ancient Greek literature saved by the TLG database (Thesaurus Linguae Graecae), to unveil fragments relative to our inquiry, in order to compose the general view of the ancient Greek medico-philosophers in the subject of the calculation of the pregnancy's duration. The terms

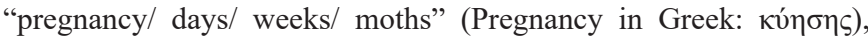

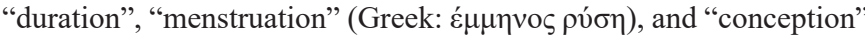
(Greek: $\sigma \dot{\prime} \lambda \lambda \eta \psi \eta \varsigma)$. 


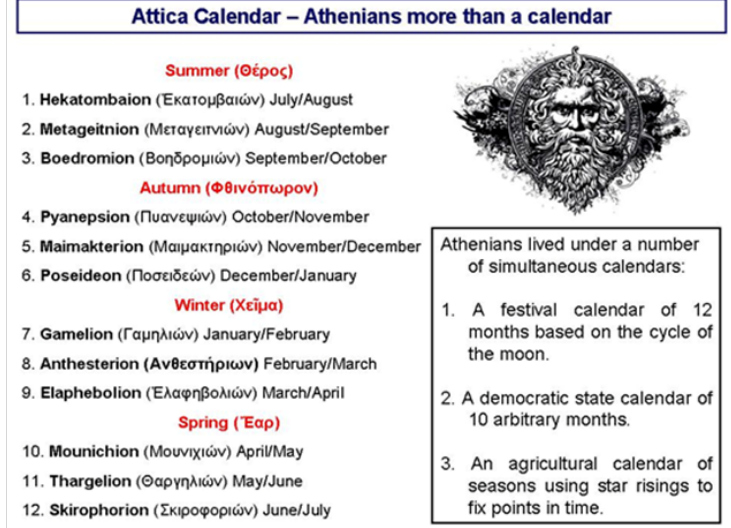

Figure 3 The Attica calendar, Athenians calendar ca $5^{\text {th }}$ century BC.

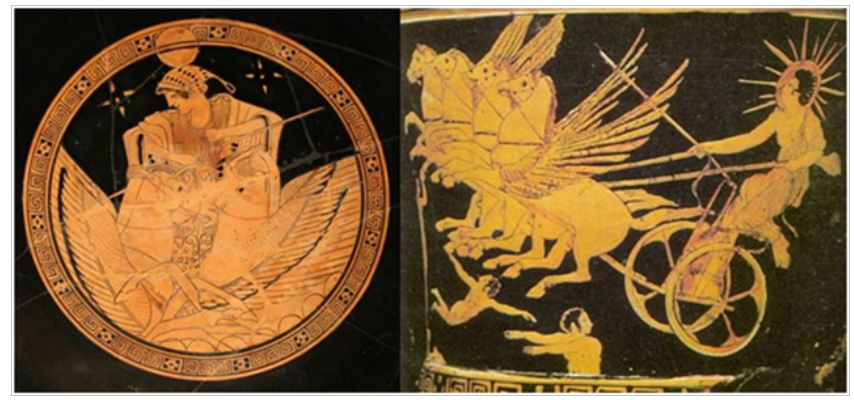

Figure 4 Selene goddess of the moon,Athenian red-figure kylix ca 5 th century BC, Antikensammlung Berlin (left side). Helius god of the sun, Athenian redfigure krater ca 5 th century BC, British Museum (right side).

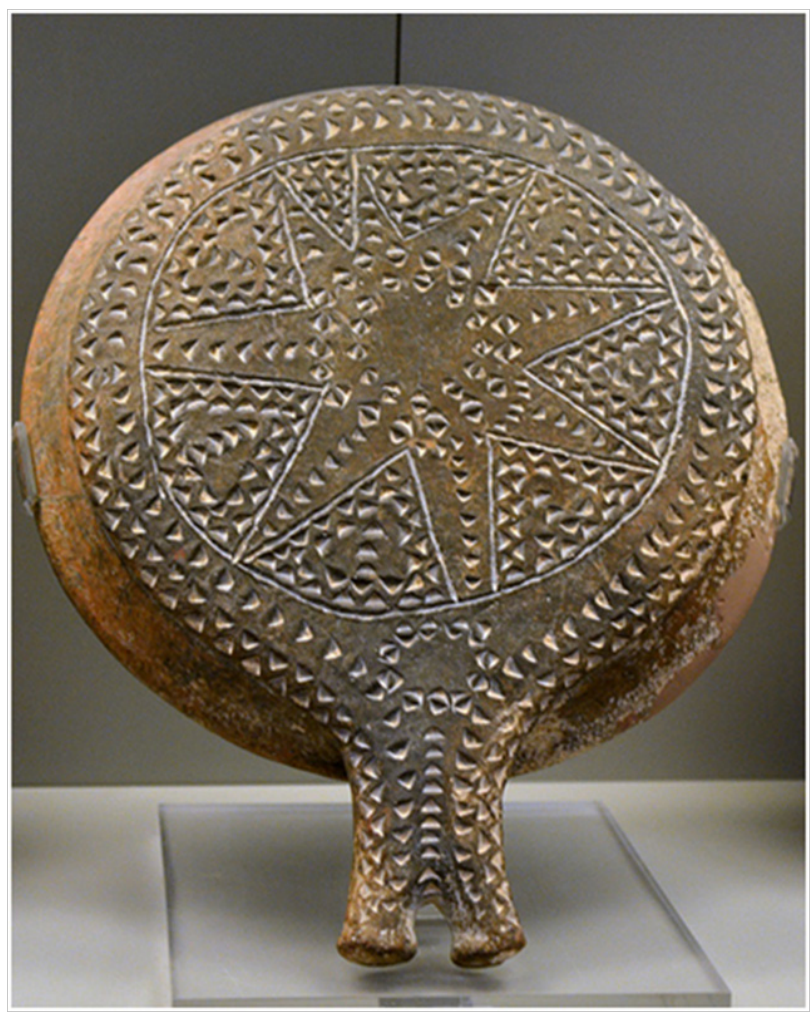

Figure 5 The "frying pan" from Chalandriani in Syros, No. 5012 at the National Archaeological Museum in Athens.

\section{"The starting point", views of the ancient Greek medicophilosophers}

Hippocrates (ca 460-370 BC) (Figure 6) defined pregnancy as a nine month process, and was the first physician who questioned the starting point for its calculation, gestational age, or fetal age "as it could be fixed by the pregnant woman who in fact tells everything", "those none months should be calculated from the date of the last menstruation cycle, or they should be calculated from the day of

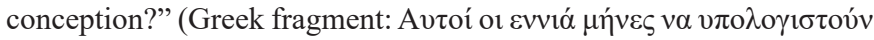

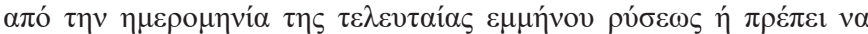

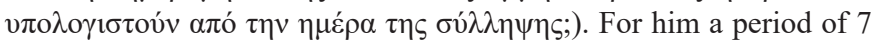
semesters of 40 days each (Greek: $\tau \varepsilon \sigma \sigma \alpha \rho \alpha \kappa o v \tau \alpha \dot{\delta} \varepsilon \varsigma)$, thus 280 days was the accurate duration for a pregnancy, to conclude that for any calculation we should trust pregnant women's information, avoiding to choose between gestational, or fetal age..$^{5-7}$
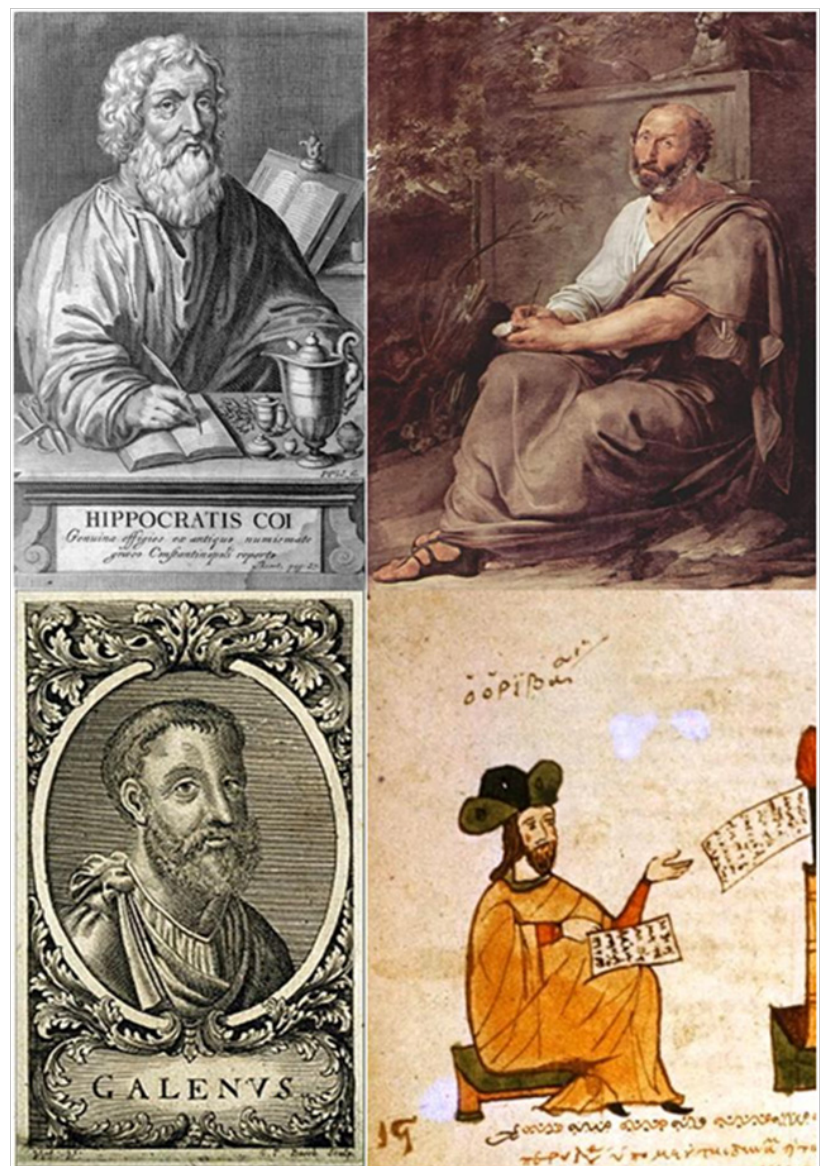

Figure 6 Hippocrates, portrait from an $18^{\text {th }}$ century edition of Hippocratic aphorisms: Hippocratis Aphorismi, König, Strasbourg, 1756 (top left side). Aristotle, portrait by Francesco Hayez (top right side). Galen, $18^{\text {th }}$ century portrait by Georg Paul Busch (bottom left side). Oribasius, Bologna, Biblioteca Universitaria, gr 3632, folio 97v (bottom right side).

Aristotle (384-322 BC) (Figure 6) introduced a new concept for the pregnancy's duration, suggesting that it is dependant to the species. Thus humans, unlike multiparous animals, give birth to one or in rare cases to two newborns, presenting a smaller pregnancy duration. According to his opinion a pregnancy could last from seven to eleven months, but normally lasts 310 days. He had also suggested that the duration is proportional to the life's duration among the species. He had also prevaricated on the question of the correct starting calculation point. ${ }^{8}$ 
Galen (ca 130-216 AD) (Figure 6), was in complete agreement with Hippocratic views. Ha had only slightly diversified on the exact pregnancy days summary, suggesting that it was 270 days, or nine months. No report concerning our quest gestational, or fetal age was mentioned inside his work. ${ }^{1,6}$
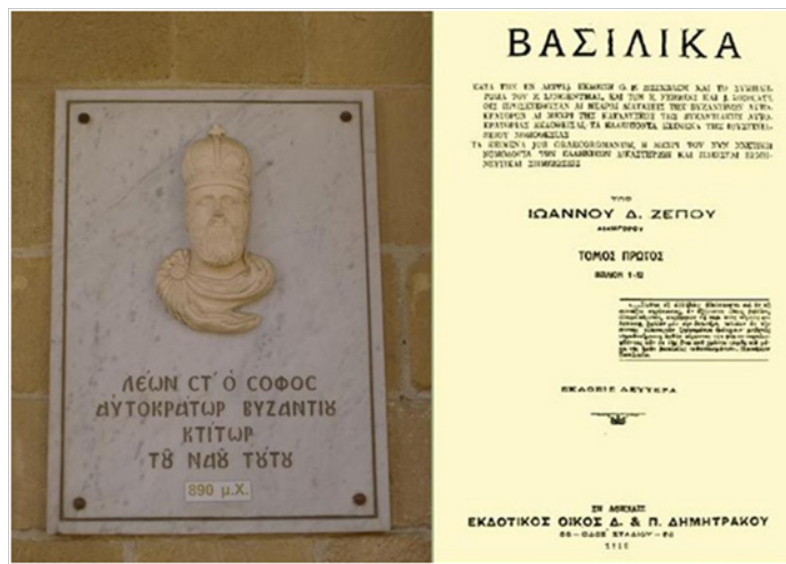

Figure 7 Emperor Leon the Wise (late $9^{\text {th }}$ - early $10^{\text {th }}$ century AD), sculpture from the "Saint Lazarus temple" in Larnaka (left side). Leon Laws (B $\alpha \sigma \lambda \lambda ı \alpha \alpha$ ) by Zepos loannis, Athens, 1910 (right side).

Oribasius (ca 320-403 AD) (Figure 6), was a pupil of Zeno of Cyprus (ca $4^{\text {th }}$ century AD) in the Alexandrian School of medicine and philosophy, a school with a notorious fame in anatomy and dissections both in humans and animals, a school pioneering in anatomy and physiology. His opinion therefore, is rather unexplained, as he suggested that pregnancy's duration could not be calculated, "pregnancy's duration is not defined, it is different even among the neonates of the same moth, for the prematures of the seven month to those born in the tenth month". He had proposed a period of 184 to 204 days as the normal pregnancy duration, "i have never seen a woman give birth before the $184^{\text {th }}$ day and after the $204^{\text {th }}$ day of

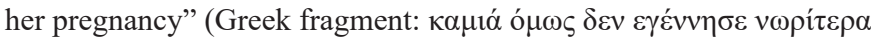

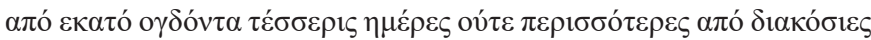
$\tau \varepsilon \dot{\varepsilon} \sigma \sigma \varepsilon p 1 \varsigma)$. No reference on the starting day for calculation once more. ${ }^{9}$
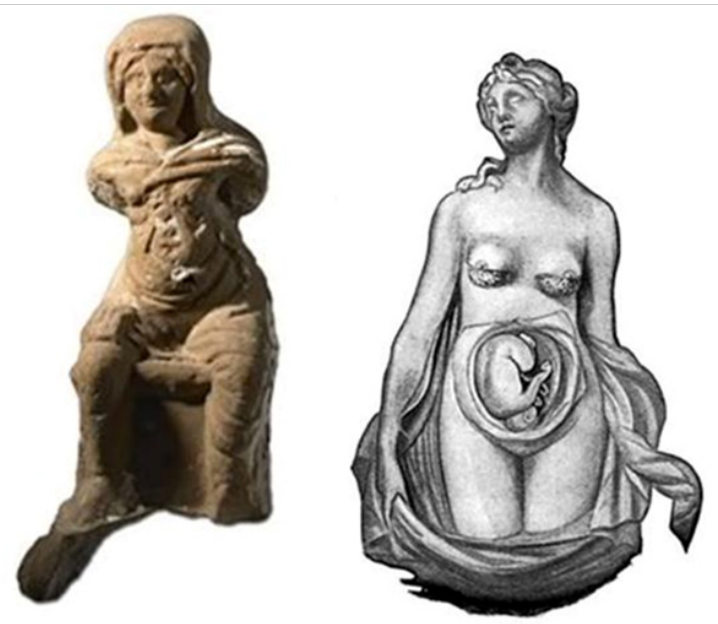

Figure 8 Ancient terracotta model of a pregnant woman (left side), representation of a wax model form inside John Hunter's book similar to the ancient one (right side).
Byzantine Empire, some eons later, introduced laws to define what a lawful pregnancy is, by adopting the ancient Greek calculation, an interval of 182 to 300 days, as it was clearly noted inside "Corpus Juris Civillis" and "Emperor Leon Laws" (Greek: B $\alpha \sigma \iota \lambda \iota \kappa \alpha ́)$ (Figure 7). It was clearly stated the for a normal 9 month newborn, the total days summary should have been 270 days, plus 5 more in the cases of a small birth delay. ${ }^{1,10}$

\section{Epilogue}

Ancient Greeks avoided to choose between gestational, or fetal age. The question raised firstly by Hippocrates remained unanswered. All medical writes referred to various theories for the total pregnancy's (Figure 8) duration, but none selected a specific starting point for the calculation. It seems that both Galenic and Hippocratic views on the days' summary 270-280 were similar to modern concepts, while the lowest summary of 184 (or 182) days is close to the birth of today's premature newborns, who may survive under special care units succour.

\section{Acknowledgments}

None.

\section{Conflicts of interest}

None.

\section{References}

1. Tsoukalas I. Paediatrics from Homer until today. Science Press, Skopelos, Thessaloniki. 2004

2. Gazzaniga V, Serarcangeli C. The ancient origins of obstetrics, a rôle for women. The ancient origins of obstetrics. Vesalius. 2000;6(1):38-41.

3. Höjeberg P. Helena Malheims barnmorskelära år 1756 (Helena Malheims' book of midwifery, year 1756), Hälsopedagogik HB, Stockholm, Sweden. 1995

4. Tsikritsis M, Moussas X, Tsikritsis D. Astronomical and Mathematical knowledge and Calendars During the Early Helladic Era in Aegean "Frying Pan" Vessel. Mediterranean Archaeology and Archaeometry. 2015;15(1):135-149.

5. Hippocrates. De morbis popularibus [Épidémies livre II] \& Du foetus de huit mois (Ed. É. Littré), Euvres complètes d'Hippocrate, volume $5 \&$ 7, Baillière, Paris, p. 118 \& 1851: 460. (repr. Amsterdam: Hakkert, 1961). 1846.

6. Galen. De Septimestri Partu. In: CG Kühn (Ed.), Claudii Galeni opera omnia. Knobloch, Leipzig, Germany, Line 25. (repr. Hildesheim: Olms, 1965). 1965.

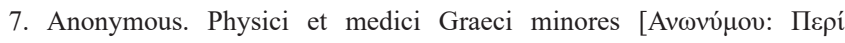

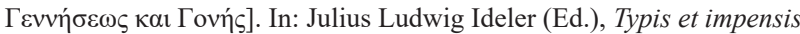
G. Reimeri, Berlin, Section 23. 1841.

8. Aristotle. Historia animalium. In: Immanuel Bekker (Ed.), Typographeo Academico, Oxford. 1837; Book 4, 777a-777b \& Book 8, 584a, $38-$ $584 \mathrm{~b}, 1$ \& 584b, 26-36.

9. Oribasius. Euvres d' Oribase [I $\alpha \tau \iota \kappa \omega ́ v ~ \Sigma v v \alpha \gamma \omega \gamma \omega ́ v, ~ K \varepsilon \varphi \alpha ́ \lambda \alpha 10$ 'I

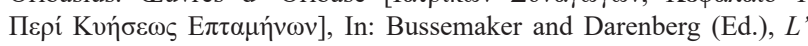
Impremerie Nationale - Baillière, Paris. 1851;4:98-99.

10. Eutichiades A. The exercise of Byzantine Medicine, Social Applications

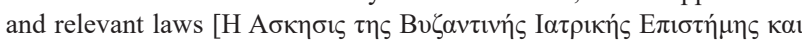

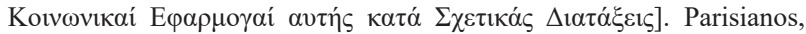
Athens. 1983;p.64. 